\title{
A agroecologia: estratégias de pesquisa e valores ${ }^{1}$
}

\author{
RUBENS ONOFRE NODARI ${ }^{I}$ \\ e Miguel PEDRo GUERRA II
}

\section{Introdução}

A SAGA humana de produção de alimentos para a sobrevivência levou a Ciência e a Tecnologia (C\&T) a dedicarem-se a sistemas agrícolas intensivos em insumos e capital sob a premissa do princípio da familiaridade, segundo o qual se avança até que se encontrem problemas. Houve de fato um aumento na produtividade dos cultivos. Entretanto, essa estratégia resultou em externalidades negativas que a C\&T não conseguem mitigar e mesmo os avanços tecnológicos, como a produção de organismos geneticamente modificados ou transgênicos, não conseguiram diminuir esses efeitos adversos ao meio ambiente e à saúde humana.

São muitas as ameaças à agrobiodiversidade, conceituada como a parte da biodiversidade utilizada pela humanidade. Não só as práticas utilizadas na agricultura industrial ou química, como também as mudanças climáticas contribuem para a extinção de espécies e para minar os processos ecológicos. As variedades transgênicas ameaçam sobremaneira a agrobiodiversidade pela contaminação por transgenes, bem como a diversidade cultural das comunidades tradicionais.

Surgem então preocupações e propostas para que sistemas agrícolas sustentáveis possam ser utilizados na produção de alimentos e outras necessidades humanas. Trata-se agora da saga pela sobrevivência não só da espécie humana, como da maioria das espécies. Uma metodologia milenar é a conservação pelo uso, na qual os agricultores de todo o mundo cultivam, conservam, produzem alimentos, fibras e outras necessidades de forma sustentável.

A agroecologia é um dos sistemas agrícolas mais sustentáveis sob todos os aspectos e propõe-se a resgatar a dignidade humana dos agricultores que ao longo da história domesticaram plantas e animais e mantiveram grande parte da diversidade genética utilizada pela espécie humana. Além disso, ao conservarem a agrobiodiversidade, esses agricultores promoveram práticas e inovações que são agora reconhecidas pela comunidade científica e pelos tomadores de decisões.

Assim, este artigo trata das ameaças à agrobiodiversidade, bem como discute oportunidades e estratégias para a conservação e o uso sustentável da diversidade genética, essencial não só para a sobrevivência da espécie humana, mas também dos processos ecológicos essenciais à manutenção da vida no planeta. 


\section{A agrobiodiversidade}

A agrobiodiversidade é a parcela da biodiversidade constituída por um conjunto de organismos e ecossistemas que apresentam fortes relações com os seres humanos, podendo ser domesticados, semidomesticados, cultivados ou manejados pelo homem. Segundo a Convenção sobre Diversidade Biológica (CDB) a agrobiodiversidade representa uma gama praticamente inesgotável de combinações entre seus quatro níveis de complexidade: diversidade dentro de espécies, diversidade entre espécies, diversidade entre ecossistemas e diversidade etnocultural. ${ }^{2}$ Nesse vasto conjunto de combinações, encontram-se componentes de alto interesse para o desenvolvimento socioambiental sustentável, com foco em comunidades rurais e locais, que representam acúmulos de conhecimentos transmitidos de gerações antepassadas, muitas vezes seculares (Stella; Kageyama; Nodari, 2006).

Essa parte da biodiversidade que serve de alimento, fonte de fibras, óleos, energia, medicamentos, entre outros usos, foi reconhecida pela civilização humana em seus primórdios, quando o homem era considerado coletor-caçador. $\mathrm{O}$ que desfrutamos hoje é resultado de práticas e inovações feitas pelos agricultores no passado, resultando na domesticação de plantas e animais. Essa expressiva diversidade genética tem sido mantida pela conservação ex situ, em bancos de germoplasma, e principalmente pelo uso sustentável e pela conservação in situ ou on farm, realizada principalmente pela agricultura familiar. Essas variedades conservadas localmente são consideradas reservatórios naturais de genes com potencial de uso para a produção sustentável de alimentos, fibras e medicamentos, entre outros. Essa diversidade genética, contudo, está sendo perdida em ritmo alarmante em razão, entre outros motivos, do crescimento desorganizado, da fragmentação dos ecossistemas naturais e da introdução de variedades exóticas melhoradas e espécies exóticas invasoras.

Como medida de prevenção ao risco de erosão genética, a CDB criou um novo marco na conservação dos recursos genéticos em âmbito mundial. Para garantir a conservação in situ ou on farm, conclamou o mundo a dar maior importância aos recursos genéticos e, em 1996, passou diretamente a abordar questões relacionadas às praticas agrícolas tradicionais, ao uso sustentável e à conservação dos recursos genéticos.

Em razão da prática histórica dos agricultores, a troca de sementes possibilitou a disseminação das espécies de plantas mais importantes para a alimentação. A grande diversidade genética existente nas variedades crioulas (ou landraces) possibilitou que a seleção natural e a seleção praticada pelos agricultores promovessem a adaptação a distintos ambientes, mesmo distantes dos centros de domesticação. Nesses locais, propriedades características foram desenvolvidas e fixadas nos diferentes genótipos, muitas delas não encontradas em outras regiões ou mesmo nas regiões de origem. Em diferentes locais foram domesticadas diferentes espécies, e embora as práticas tenham sido semelhantes, as espécies 
domesticadas e os seus usos foram associados aos valores culturais e aos ritos dos habitantes e comunidades daquelas regiões. Assim, nesses centros a diversidade genética é resultado de fatores de natureza histórica, ecológica, genética e cultural. Configura-se, assim, um processo coevolutivo no qual a cultura humana moldou e adaptou os sistemas biológicos, e estes moldaram a cultura (Norgaard, 1989).

As variedades crioulas (no Brasil também chamadas de locais e tradicionais) das principais culturas e das espécies regionais subutilizadas geralmente apresentam boas qualidades nutricionais e estão bem adaptadas às condições ecológicas locais e necessitam baixas quantidades de insumos agrícolas. Comparativamente às variedades crioulas, as variedades modernas apresentam uma constituição nutricional mais pobre em vários nutrientes (Davis, 2009; Davis; Epp; Riordan, 2009). Esses autores verificaram que os teores de treze nutrientes e da água declinaram, comparativamente aos dados do Departamento de Agricultura dos Estados Unidos (USDA) publicados entre 1950 e 1999, para 43 cultivos, a maioria de plantas hortícolas. Esse empobrecimento nutricional foi mais expressivo para seis nutrientes (proteínas, cálcio, fósforo, ferro, riboflavina e ácido ascórbico). Cabe destacar que essa diminuição foi de $6 \%$ para as proteínas a 38\% para a riboflavina. A hipótese mais provável para explicar essas ocorrências é de que o melhoramento genético privilegiou mais o rendimento (geralmente visando o acúmulo de amido ou massa foliar), em detrimento do acúmulo de outros nutrientes e vitaminas essenciais, configurando um efeito de diluição. Para o caso do brócolis, os teores médios de cálcio analisados nas variedades híbridas modernas foram de $3,4 \mathrm{mg} / \mathrm{g}$, valores esses expressivamente mais baixos do que aqueles observados nas variedades da década de $1950(12,9 \mathrm{mg} / \mathrm{g})$ e do ano de $1963(9,4 \mathrm{mg} / \mathrm{g})$. Concluíram os autores que qualquer redução nos teores nutricionais é geralmente mais bem explicada pelas mudanças nas cultivares entre 1950 e 1999, e que realmente pode ter ocorrido uma relação inversa entre rendimento e conteúdo de nutrientes.

Por que as variedades crioulas são consideradas como um recurso genético que contém genes para a adaptação a distintos ambientes e necessidades da civilização humana? Porque "variedade crioula é uma variedade local ou regional de domínio das comunidades indígenas, tradicionais locais ou de pequenos agricultores, que consiste de genótipos com uma ampla diversidade genética, adaptados a hábitats específicos, como resultado da seleção natural combinada com a pressão de seleção humana sobre o meio ambiente local" (Stella; Kageyama; Nodari, 2006 , p.54). As características das variedades crioulas permitem o seu uso potencial para a produção sustentável de elementos essenciais para a humanidade, tais como alimentos, fibras e medicamentos, entre outros. E essa agrobiodiversidade tem sido obtida e mantida por populações tradicionais (Tuxill, 2000).

Para tornar operacional o manejo sustentável e o melhoramento por meio do manejo e práticas participativas, a existência de diversidade genética é impres- 
cindível. Da mesma forma, as mudanças climáticas globais fortalecem e ampliam a necessidade de conservação e a utilização desses recursos genéticos.

Quando se consideram as práticas agroecológicas, a agrobiodiversidade também é imprescindível, pois um dos princípios ecológicos mais importantes nos quais essas práticas se fundamentam é a diversidade de espécies e a diversidade intraespecífica nos agroecossistemas.

\section{Conservação in situ ou on farm}

Maxted et al. (1997, p.340) definiram conservação in situ ou on farm como "o manejo sustentável da diversidade genética de variedades agrícolas tradicionais localmente desenvolvidas, associadas a formas e parentes silvestres e desenvolvidas por agricultores dentro de um sistema de cultivo agrícola, hortícola ou agroflorestal tradicional". Esse tipo de conservação, praticada há milênios pelos agricultores, fundamenta-se em um contínuo processo de evolução e adaptação, no qual novos variantes surgem e são desafiados pela seleção natural e artificial (Stella; Kageyama; Nodari, 2006).

Há muitas razões para justificar a necessidade da conservação on farm. Brush (2000a) cita as seguintes:

(1) elementos-chave dos recursos genéticos dos cultivos não podem não ser capturados e mantidos fora da área de cultivo;

(2) os agroecossistemas continuam a gerar novos recursos genéticos;

(3) a necessidade de manutenção em campo de uma duplicata do banco de germoplasma;

(4) os agroecossistemas em centros de diversidade ou de evolução se constituem em laboratórios naturais para pesquisa agrícola.

Do ponto de vista dos pequenos agricultores, a razão mais importante para eles manterem a diversidade genética em cultivo em suas propriedades é o valor direto desses recursos genéticos (Brush, 2000a). Isso inclui o valor das colheitas, o uso comercial ou não (por exemplo, consumo) e a industrialização. Além disso, os recursos genéticos mantidos em cultivo apresentam atributos de qualidade diferenciais associados ao sabor e características dos alimentos, que remetem à tradição e a ritos culturais ou místicos. Adicionalmente, vale destacar o valor indireto desses recursos genéticos, já que as variedades locais mantêm uma relação evolutiva com o ambiente circundante e as práticas agrícolas empregadas.

A diversidade permite a utilização de práticas ecológicas associadas aos policultivos ou cultivos consorciados, seja de espécies anuais ou na forma de sistema agroflorestais. Por sua vez, esses sistemas favorecem outros processos ecológicos tais como a fixação biológica do nitrogênio atmosférico, que é um processo mediado pela associação entre bactérias e certas plantas (notadamente leguminosas) que, por sua vez, beneficiam outras plantas não fixadoras de nitrogênio. Outro valor indireto é a possibilidade de uso futuro, também denominado valor de opção, quando o agricultor mantém certas variedades prevendo sua utilização futura (Brush, 2000a). 
A razão mais importante, entretanto, está relacionada com o papel histórico dos agricultores no desenvolvimento de práticas e inovações. Sem diversidade, não há como fazer inovações (por exemplo, selecionar um novo tipo de planta), tampouco criar práticas de cultivos diferenciados (por exemplo, combinações de espécies e épocas de cultivo), e muito menos adaptar as variedades a distintos ambientes e épocas de cultivo. Sem essa oportunidade, os agricultores deixam de realizar seu papel histórico de agentes da conservação e do uso sustentável da agrobiodiversidade.

As sociedades e comunidades tradicionais, que compreendem os povos indígenas, quilombolas, afrodescendentes, sertanejos, caiçaras, caboclos, extrativistas e, por fim, o campesinato em toda a sua sociodiversidade, caracterizam-se por sua dependência em relação aos recursos naturais (Silva, 2008).

\section{$\mathrm{O}$ desenvolvimento da agricultura industrial}

Se, de um lado, os campesinos e, posteriormente, a agricultura familiar encarregaram-se de desenvolver inovações e práticas ecológicas para o cultivo de plantas e a criação de animais, de outro, a ciência e a tecnologia encarregaram-se de desenvolver conhecimento e técnicas que modificaram completamente a agricultura praticada até meados do século passado.

O conjunto de práticas da agricultura industrial ou química atualmente predominante teve suas bases estabelecidas há sessenta anos, constituindo a chamada "revolução verde". Decorrente de avanços científicos e técnicos, essas práticas englobam a utilização de variedades de alta produtividade, o uso intenso de agroquímicos (em particular, agrotóxicos) e suas consequências (Antoniou et al., 2012), irrigação, maquinaria agrícola e políticas públicas de apoio, entre outras. Em decorrência, a produção de grãos dobrou de um para dois bilhões de toneladas/ano entre 1966-1999. Para tanto, houve incremento de 97\% de áreas irrigadas e aumento de $638 \%$ no uso de adubos nitrogenados, de $203 \%$ na utilização de fosfatos e de $854 \%$ na aplicação de agrotóxicos.

As externalidade negativas mais significativas das práticas agrícolas decorrentes da revolução verde foram:

(1) a extinção e fragmentação de hábitats, decorrentes da ampliação das fronteiras agrícolas e da não observância de normas ambientais, resultando no declínio da biodiversidade e na degradação ambiental;

(2) a emissão de gases (principalmente gás carbônico, óxido nitroso e metano) com reflexos diretos sobre as mudanças climáticas;

(3) os impactos socioculturais, associados ao êxodo rural, à desagregação social das comunidades e à perda dos ritos culturais e das boas práticas agrícolas, que foram substituídas por esse novo modelo agrícola.

Mesmo com o advento dos agrotóxicos, em particular dos inseticidas, e das práticas integradas de manejo de pragas, a produção mundial dos principais cultivos ainda é afetada por pragas pré e pós-colheita causadoras de expressivas perdas (Kogan; Bajwa, 1999). Esses autores constataram que as perdas agrícolas 
ao longo de diferentes épocas do século XX causadas por insetos variaram de 7\% a $34 \%$ com o uso de inseticidas, comparativamente a $18 \%$ sem o uso dos referidos agrotóxicos. As perdas causadas pelas doenças variaram de $10 \%$ a $12 \%$, pouco menos do que $15 \%$ sem o uso de fungicidas. O controle de plantas espontâneas com herbicidas foi pouco eficiente no século XX, pois as perdas, mesmo com o uso dos referidos produtos químicos, ainda variaram de $8 \%$ a $12 \%$, comparativamente às perdas de $9 \%$ sem o uso desses produtos.

A primeira Avaliação Internacional do Impacto da Ciência e Tecnologia na Agricultura para o Desenvolvimento (IAASTD) foi concluída em 2008. Essa avaliação teve início em agosto de 2002 quando o Banco Mundial e o Programa das Nações Unidas para a Agricultura e Alimentação (FAO) deflagraram um processo para acessar a avaliação do conhecimento, ciência e tecnologia na agricultura, ao qual se juntaram o Global Enviromental Fund (GEF), United Nations Environmental Programme (Unep), United Nations Educational, Scientific and Cultural Organization (Unesco), United Nations Development Programme (UNDP) e a World Health Organization (WHO) como patrocinadores, além de ONG e aproximadamente quatrocentos cientistas como atores. Após uma sequência de reuniões decidiu-se que essa avaliação deveria ser multitemática, multiespacial, multitemporal, multiatores e fundamentada em relatórios e documentos, alguns estabelecidos por regiões geográficas (por exemplo, América Latina e Caribe), outros agrupados por temas (por exemplo, biotecnologia) e outros resultando de sínteses regionais e globais. ${ }^{3}$ Os objetivos de desenvolvimento e sustentabilidade do IAASTD são consistentes com os objetivos da Avaliação do Milênio: reduzir a pobreza e a fome, melhorar a nutrição e a saúde humana, melhorar as condições de vida na área rural e facilitar o desenvolvimento sustentável de forma justa, econômica, social e ambiental. Esses objetivos postulam uma agricultura multifuncional mesmo diante das ameaças dramáticas das mudanças climáticas, o crescimento de demandas e da população e a depleção dos recursos naturais. O IAASTD (2008) discutiu assuntos críticos e forneceu informações para que os tomadores de decisão confrontem visões conflitantes de tópicos associados às consequências ambientais do aumento da produtividade, os impactos na saúde humana e no meio ambiente de plantas transgênicas, as consequências da produção de bioenergia, bem como as implicações das mudanças climáticas na produção agrícola.

A principal conclusão do IAASTD foi a de que o modelo de negócios até então adotado nestes últimos cinquenta anos não é uma opção (business as usual is not an option) porque, nesse período, a agricultura tem sido caracterizada por desconexões, tanto em países desenvolvidos quanto nos países em desenvolvimento:

(1) desconexão entre a agricultura e o meio ambiente;

(2) desconexão entre agricultores e consumidores;

(3) desconexão entre políticas e consequências (esperadas ou não esperadas). 
Tanto as pesquisas para o desenvolvimento da agricultura industrial quanto para a biotecnologia moderna foram baseadas na simplificação e individualização das atividades agrícolas. Essa aposta em alguns fatores e não nas interações entre ambos e com outros fatores do ecossistema é considerada como a causa principal das consequências mencionadas. Ao contrário da visão majoritária da biologia molecular que vem sendo praticada, o problema da biologia é que, em contraste com outros ramos do mundo físico, nos quais poucas grandes forças dominam os fenômenos, o organismo vivo é resultante de um grande número de determinantes causais fracos, fazendo que seja extremamente difícil proporcionar explanações completas em um universo tão complexo (Lewontin, 2000). $\mathrm{O}$ autor menciona ainda que um organismo vivo em um momento qualquer de sua vida é a consequência única da história do desenvolvimento, a qual resulta de interações e determinações de forças internas e externas. Essas forças externas, que usualmente pensamos como ambiente, são em parte consequências do próprio organismo. Os organismos não encontram o mundo onde se desenvolvem, mas o fazem. Reciprocamente, as forças internas não são autônomas, mas agem em resposta às externas.

\section{Ameaças à agrobiodiversidade e à conservação in situ ou on farm}

Toda a riqueza de recursos genéticos associados às variedades crioulas, base da segurança alimentar e componente substancial da economia de vários países, encontra-se sob ameaças crescentes; por um lado, pela ação antrópica (em virtude do tipo de agricultura predominante), e, por outro lado, pelos efeitos das mudanças climáticas.

A biodiversidade vem sendo destruída em um ritmo alarmante em razão do crescimento desordenado e da exploração incontrolada dos recursos naturais e dos ecossistemas (Maxted et al., 1997). O modelo industrial da produção agrícola baseado nos princípios da revolução verde, intensificado desde 1960 com suas variedades comerciais ganhando cada vez mais importância, resultou no abandono de muitas variedades locais e, em consequência, em sua erosão genética (Clement et al., 2004).

Além das ameaças passadas, as ameaças futuras podem restringir ainda mais o uso desses recursos genéticos vegetais de importância alimentar. Assim, uma das consequências mais preocupantes do cultivo de variedades transgênicas é a contaminação genética, pelos transgenes, de variedades crioulas ou populações silvestres de uma espécie cultivada, cultivadas ou mantidas pelos pequenos agricultores em centros de origem ou de diversidade genética (Nodari; Guerra, 2004). Transgenes são os genes modificados inseridos em variedades transgênicas e essa contaminação genética tem muitas consequências (Ellstrand, 2003). As variedades crioulas são cultivadas prioritariamente para a alimentação humana e seus produtos são típicos da cultura das comunidades. Atualmente essas variedades estão sendo contaminadas principalmente com transgenes que produzem toxinas (oriundas da bactéria Bacillus thuringiensis, por isso o nome de toxinas $\mathrm{Bt}$ ). 
Também o reservatório genético, o qual é uma fonte de variabilidade genética, é prejudicado em diferentes formas pela contaminação genética por meio de:

(1) aumento de risco de extinção em decorrência da hibridação ou competição com esses organismos;

(2) disseminação de um genótipo, o qual às vezes sobrepõe-se aos tipos locais, tanto por deslocamento, quanto por hibridação, aumentando assim a probabilidade de extinção, inclusive de populações raras;

(3) a fração dos híbridos produzidos pelas populações raras pode ser tão alta que a população local (landrace) torna-se geneticamente absorvida pela variedade transgênica (assimilação genética) (Ellstrand, 2003).

Para os agricultores, as consequências da contaminação genética são:

(1) a diminuição da diversidade genética em cultivo, em razão do pequeno número de variedades transgênicas disponíveis, caracterizando uma condição de vulnerabilidade genética;

(2) a redução da fonte de novos alelos ou combinações alélicas tanto para a seleção praticada pelos agricultores em suas propriedades quanto para os programas de melhoramento genético;

(3) a corrosão dos efeitos da seleção natural a favor da adaptação aos ambientes locais (Ellstrand, 2003; Nodari et al., 2011).

Ao contrário de contribuir, os transgênicos reduzem as chances de inovações e a manutenção dos conhecimentos das comunidades locais e indígenas limitando determinadas práticas, entre elas a troca e a seleção de sementes. Em particular, a perda do conhecimento tradicional, pela dependência da compra anual de sementes e insumos associados, poderá causar uma mudança drástica em termos de sustentabilidade e estabilidade das comunidades locais e indígenas, decorrente da insegurança alimentar.

Existem poucas dúvidas de que fragmentos isolados de vegetação natural em uma paisagem antrópica, tal como uma plantação de banana sob constante pulverização de agrotóxicos, constituem-se em receitas de desastre do ponto de vista da preservação da biodiversidade. Essas paisagens agrícolas monoespecíficas são uma redução efetiva do potencial migratório necessário para que uma metapopulação possa ser conservada em longo prazo (Perfecto; Vandermeer; Wright, 2009).

As mudanças climáticas também trarão consequências na adaptação das espécies e das variedades existentes para a produção de alimentos. De fato, as mudanças climáticas converteram-se em grave problema para a humanidade e comprometem a viabilidade de grande número de espécies, em particular a riqueza da agrobiodiversidade. Nesse sentido, o Painel Intergovernamental sobre Mudanças Climáticas, por meio de seu quarto relatório disponibilizado em 2007 , previu que de $25 \%$ a $30 \%$ das espécies de plantas serão extintas ou estarão ameaçadas de extinção ao longo do século XXI. 
Em 1990, cientistas do clima do mundo todo divulgaram o Primeiro Relatório de Avaliação do Painel Intergovernamental sobre Mudança do Clima (IPCC). ${ }^{4}$ Esse relatório continha uma previsão da tendência da temperatura global média durante o período de 1990-2030 que, agora avaliadas no meio desse período, parecem precisas (Frame; Stone, 2013). Os autores ainda afirmaram que, como é sempre o caso na ciência, não podemos saber com certeza que as previsões feitas em 1990 eram de fato precisas pelos motivos certos, mas, dada a conformação das previsões, é possível reconhecer a robustez da previsão. Assim, o clima está respondendo ao aumento dos níveis de gases de efeito estufa, de acordo com as expectativas históricas.

O Quinto Relatório do IPCC foi parcialmente disponibilizado em 2013. Resumidamente, o aquecimento do sistema climático é inequívoco e, desde a década de 1950, muitas das mudanças observadas não encontram precedentes ao longo de milênios. A atmosfera e os oceanos aqueceram, a quantidade de neve e gelo tem diminuído, o nível do mar subiu, e as concentrações de gases de efeito estufa aumentaram.

Mais especificamente: (1) cada uma das três últimas décadas tem sido sucessivamente mais quente na superfície da Terra do que qualquer década anterior desde 1850. No Hemisfério Norte, o período 1983-2012 foi provavelmente o mais quente dos últimos 1.400 anos; (2) a taxa de aumento do nível do mar desde meados do século XIX foi maior do que a taxa média observada durante os dois milênios anteriores. Durante o período de 1901-2010, o nível médio do mar global aumentou 0,19 m; (3) as concentrações atmosféricas de gases de efeito estufa, entre eles dióxido de carbono $\left(\mathrm{CO}_{2}\right)$, metano $\left(\mathrm{CH}_{4}\right)$ e óxido nitroso $\left(\mathrm{N}_{2} \mathrm{O}\right)$, aumentaram desde 1750 em razão da atividade humana. Em 2011, as concentrações desses gases de efeito estufa foram de $391 \mathrm{ppm}, 1.803 \mathrm{ppb}$ e $324 \mathrm{ppb}$, e superaram os níveis pré-industriais em cerca de $40 \%, 150 \%$ e $20 \%$, respectivamente. As concentrações de $\mathrm{CO}_{2}, \mathrm{CH}_{4}$ e $\mathrm{N}_{2} \mathrm{O}$ agora excedem substancialmente as concentrações mais altas registradas em núcleos de gelo durante os últimos oitocentos mil anos. As taxas médias de aumento das concentrações atmosféricas ao longo do século passado não têm precedentes nos últimos 22 mil anos; (4) a mudança de temperatura da superfície global prevista para o final do século XXI é susceptível de ultrapassar em $1,5^{\circ} \mathrm{C}$ os valores observados entre 1850-1900 para quase todos os cenários avaliados. É provável que possa aumentar em mais de $2{ }^{\circ} \mathrm{C}$ para certos cenários; (5) as mudanças no ciclo global da água em resposta ao aquecimento ao longo do século XXI não serão uniformes. O contraste entre a precipitação nas regiões úmida e seca vai aumentar, embora possa haver exceções regionais.

Já existem muitos estudos sobre os impactos das mudanças climáticas na agricultura. Um exemplo disso é relacionado à batata, um dos alimentos mais importantes da humanidade. Com o aumento médio da temperatura na região de origem, a espécie de batata Solanum demissum, que é resistente a uma podri- 
dão causada pelo oomiceto Phytophthora infestans (a mesma doença que dizimou a produção de batata na Irlanda na década de 1840, sendo a causa da histórica grande fome), perderá de $10 \%$ a $67 \%$ de seu hábitat natural. Outras espécies de batata como $S$. chacoense e $S$. berthaultii, resistentes ao besouro da batata, perderão $40 \%$ a $53 \%$ e $2 \%$ a $65 \%$ da sua área de distribuição, respectivamente. Já a espécie $S$. microdontum, que pode ser utilizada no melhoramento genético para aumento do conteúdo de cálcio, poderá perder $9 \%$ de sua área (Jarvis et al., 2008). Em todos os casos, as mudanças climáticas diminuirão a área adequada para o desenvolvimento dessas espécies e, consequentemente, haverá erosão genética, com a perda de populações de plantas. A riqueza de espécies diminuirá mais em baixas altitudes, porque as áreas adequadas para essas espécies mover-se-ão para regiões mais altas em razão do aumento da temperatura nas áreas de baixa altitude. Grandes perdas em termos de riqueza de espécies deverão ocorrer nas latitudes $20-25^{\circ} \mathrm{N}$ e $20-40^{\circ} \mathrm{S}$.

Ante as ameaças, as comunidades agrícolas e os povos indígenas ou tradicionais podem ser parte da mitigação eficaz e da adaptação aos efeitos das mudanças climáticas e outros perigos, já que essas comunidades mantêm em cultivo uma ampla gama de materiais genéticos. Para tanto, eles não necessitam destruir ou simplificar ao extremo os sistemas naturais. Ao contrário, manejam os agroecossistemas e a biodiversidade agrícola utilizando os princípios e processos agroecológicos, que garantem a sustentabilidade.

\section{Os sistemas agrícolas alternativos do século $\mathrm{XX}$}

A agricultura denominada convencional, resumidamente, utiliza insumos químicos tais como fertilizantes (em quantidades dependentes de cada solo e cultivo), bem como agrotóxicos, além da mecanização intensiva e de sementes de alto potencial que se expressa em ambientes modificados, muitas vezes com irrigação. Essa agricultura convencional consolidou-se ainda no século XX, decorrente também dos avanços científicos, produzidos em particular pelos estudos de Carl Sprengel, no início do século XIX, posteriormente popularizados por Justus von Liebig. Em 1840, Liebig publicou o livro Aplicações da química orgânica na agricultura e fisiologia (Whitson; Walster, 1912). A chamada lei de Liebig, também conhecida por "lei do mínimo", é um princípio utilizado principalmente na agricultura, segundo o qual o crescimento das plantas é controlado pelo recurso mais escasso (fator limitante) e não pela quantidade total de recursos disponíveis. Assim, teve início a prática do uso de fertilizantes sintéticos na agricultura. Atualmente é prática corrente da agricultura convencional basear-se em análise de solo para efetuar a estimativa da necessidade de uso de fertilizantes, exatamente como previsto por Liebig. O mesmo princípio foi posteriormente estendido para o uso de agrotóxicos, que se baseia em índices de infestação de pragas ou patógenos, embora haja também a recomendação de técnicos para fumigações ditas "preventivas".

Enquanto a agricultura convencional estava estabelecendo-se, outros sistemas agrícolas foram igualmente concebidos e praticados. Trata-se de sistemas 
alternativos de agricultura, os quais valorizam o uso da matéria orgânica e os processos biológicos. Em 1924, foram estabelecidas por Rudolf Steiner (1976) as bases da agricultura biodinâmica. Do ponto de vista mais geral, os biodinâmicos propugnam uma abordagem mais integrada da propriedade rural, procurando vê-la e manejá-la como um organismo vivo. Essa abordagem data da década de 1920, muito antes de as ideias ecológicas serem respeitadas e adotadas, e bem antes da teoria Gaia ser estabelecida.

Quase simultaneamente, a agricultura orgânica foi proposta por Albert Howard (1943), que escreveu o livro An agricultural testament [Um testamento agrocultural]. Posteriormente outros autores reforçaram a base teórica e propuseram práticas de produção orgânica. Atualmente existe a Federação Internacional dos Movimentos de Agricultura Orgânica (Ifoam), entidade com sede em Tholley-Thelley, na Alemanha, que organiza eventos sobre a produção orgânica.

A permacultura é um sistema de agricultura ecológica desenvolvido por Bill Mollison na Austrália (Mollison; Holmgten, 1978). Apresenta uma visão holística da agricultura, buscando a integração entre a propriedade agrícola e o agroecossistema, com um modelo de sucessão de cultivos visando otimizar a produção e conservando os recursos naturais.

A agroecologia, que tem como variantes a agricultura ecológica, a agricultura alternativa e a agricultura sustentável, entre outras, vem sendo desenvolvida e aprimorada desde o surgimento dos demais sistemas agrícolas do século passado. Assim, considera-se a agroecologia como o paradigma emergente, substituto da agricultura industrial ou convencional, exatamente por incorporar elementos de síntese, unificadores, integradores. Esse novo paradigma diferencia-se por ter uma abordagem holística, não apenas no que concerne às questões ambientais quanto, sobretudo, às questões humanas (Jesus, 2005). Esse autor descreve ainda outros sistemas não convencionais de agricultura.

Já na primeira versão de seu livro Agroecology [Agroecologia], Gliessman (1990) admitia haver um fecundo diálogo entre agrônomos e ecólogos, de maneira a fortalecer agendas comuns na busca de formas sustentáveis de produção de alimentos. O relançamento de seu livro (Gliessman, 1998), ampliado e atualizado, constitui enorme contribuição aos estudantes da agroecologia.

Pouco antes, Miguel Altieri (1987) e outros cientistas que colaboraram em seu livro constituíram-se em importantes autores no que tange à popularização da agroecologia, como um novo marco conceitual científico e de desenvolvimento, incorporando a noção de conhecimento indígena e tradicional, aspectos culturais, manejo ecológico de pragas, manejo da biodiversidade, aspectos socioeconômicos, educação em agroecologia, entre outras coisas, e apresentando uma contribuição decisiva na evolução conceitual com relação às formas de agricultura não convencionais. O coração da agroecologia, segundo Altieri (1999), reside na ideia de que um campo de cultivo é um ecossistema dentro do qual ocorrem outras formações vegetais, ciclagem de nutrientes, interações e suces- 
sões; e, por meio do conhecimento desse processo de relações nos sistemas, esses podem ser mais bem administrados com menos impactos negativos ao meio ambiente e à sociedade e com menor uso de insumos externos.

A agroecologia se fundamenta em uma base epistemológica distinta dos princípios da tradicional ciência ocidental. O paradigma agronômico tradicional considera o desenvolvimento da agricultura e dos agricultores a partir da difusão de tecnologias cientificamente validadas. O paradigma agroecológico procura entender as bases ecológicas que fundamentam os sistemas agrícolas tradicionais para, a partir daí, desenvolver uma agricultura moderna mais sustentável. (Norgaard, 1989, p.47)

"Os agroecologistas", segundo esse autor, "estão mudando a direção de mão única predominante nos caminhos entre a ciência e o desenvolvimento e introduzindo a mão dupla". Noorgaard $(1989$, p.44) prevê ainda que "se a comunidade científica puder lidar com duas bases epistemológicas de pensamento, as próximas décadas poderão tornar-se inovadoras tanto para as ciências agrícolas, quanto para as políticas de desenvolvimento".

Além da concepção como sistema agrícola, a agroecologia possui outros significados. Segundo Padua (2001, p.111), “a agroecologia é muito mais do que uma forma de gestão de recursos naturais, configurando-se como um novo modo de vida rural, capaz de conjugar valores, qualidade de vida, trabalho, renda, democracia, emancipação política, em um mesmo processo". Comparativamente à revolução verde, a agroecologia é menos dependente de insumos, é mais eficiente energeticamente, usa menos capital e é mais ambientalmente sustentável.

Técnicas associadas à agroecologia que conservam recursos e utilizam poucos insumos externos vêm revelando potencial para melhorar significativamente os rendimentos. Em um estudo conduzido por Pretty et al. (2006) foram analisados 286 projetos de agricultura sustentável de 57 países pobres, totalizando uma superfície de 37 milhões de ha ( $3 \%$ da superfície cultivada nos países em desenvolvimento). Os autores concluíram que essas técnicas que conservam recursos e utilizam poucos insumos externos haviam aumentado a produtividade de 12,6 milhões de propriedades agrícolas, com aumento médio de 79\% nas colheitas, ao mesmo tempo que houve melhoria na oferta de serviços ambientais essenciais. $\mathrm{O}$ aumento no rendimento foi de $1,7 \mathrm{t} / \mathrm{ha}$ anuais para 4,42 milhões de pequenos agricultores que cultivaram cereais e tubérculos. Aumentos de até $17 \mathrm{t} / \mathrm{ha}$ foram alcançados por 146 mil agricultores que cultivaram tubérculos (batata, batata-doce e mandioca). Em outro estudo (Badgley et al., 2007), foi feita a comparação de rendimentos entre os sistemas convencional (alto uso de insumos) e o orgânico (baixo uso de insumos). Para a maioria das categorias de alimentos, a média de rendimento dos cultivos no sistema orgânico foi levemente menor do que no sistema convencional nos países desenvolvidos. Entretanto, os autores verificaram que nos países em desenvolvimento os cultivos orgânicos rendiam mais do que no sistema convencional. 
O Sistema Agroflorestal (SAF), que utiliza princípios e processos agroecológicos, também tem sido avaliado. Por exemplo, no Malawi, o uso de árvores fixadoras de nitrogênio atmosférico no $\mathrm{SAF}$, o que possibilita produzir sem o seu aporte externo, aumentou o rendimento de milho em 1 a $3 \mathrm{t} / \mathrm{ha}$ (Garrity et al., 2010).

\section{Conhecimentos necessários e lacunas no conhecimento}

Modelos de agricultura alternativa à convencional incorporam complexidade, incerteza e transdisciplinaridade, de modo que o conhecimento científico e os saberes tradicionais devem ser empregados simultaneamente (Gomes; Borba, 2000). Mais do que isso, a agroecologia permite que a agricultura se torne também multifuncional. Embora apropriada para pequenas propriedades, há práticas agroecológicas que podem também ser utilizadas em propriedades médias e grandes.

Os desafios do conhecimento pertinente à agroecologia são muito maiores do que aqueles gerados e empregados no âmbito da revolução verde. São também de natureza ética distinta. Assim, a pesquisa científica pode ser conduzida sob um pluralismo de estratégias, não apenas aquelas que se encaixam na abordagem descontextualizada, mas outras que permitem investigação empírica que levam completamente em conta as dimensões ecológicas, experienciais, sociais e culturais de fenômenos e práticas (como a agroecologia). Essa é a reivindicação do pluralismo metodológico (Lacey, 2005) que se dedica à pesquisa contextualizada.

Um sistema agroecológico é mais complexo do que um monocultivo. Considerando que nessas paisagens agrícolas há uma ampla diversidade de espécies, ao invés dos efeitos individuais de cada componente do sistema, as interações passam a ser predominantes. Isso configura sistemas de produção intensivos em conhecimento e que levam em consideração as múltiplas dimensões da sustentabilidade nos seus níveis econômicos, sociais, culturais, ecológicos, políticos e éticos. Por isso, o diálogo entre os saberes tradicionais e o conhecimento científico transforma e renova o conhecimento científico e todas as demais formas de conhecimento, gerados em comunidades com pluralidades socioculturais e territoriais.

Há muitos fatores favoráveis nesse contexto e associados, por exemplo, à grande diversidade existente entre as comunidades nos seus aspectos culturais, étnicos, de ecossistemas, de conhecimentos e práticas desenvolvidas e acumuladas e, por fim, de capacidade de inovação. Dessa forma, comparativamente aos sistemas de agricultura convencional, há a necessidade de reorientação dirigida à sustentabilidade, em que há a priorização do uso de mais biodiversidade, de práticas agroecológicas e do manejo integrado dos recursos naturais. Assim, a visão holística está perfeitamente adequada à agroecologia.

Também a agroecologia torna-se a condição básica para a multifuncionalidade da agricultura, tão apregoada pelos organismos intergovernamentais há 
dezenas de anos. Há exemplos na literatura científica sobre a diversificação dos sistemas agrícolas, tais como os policultivos, o cultivo em faixas e os sistemas agroflorestais (Badgley et al., 2007). Mesmo um aumento mínimo de diversidade em cultivo, tal como a mistura de sementes de duas ou mais variedades, pode aumentar a produção reduzindo os custos. Ensaios contemplando a mistura de duas variedades de café conduzidos no Brasil mostraram incrementos de até 50\% na produção, comparativamente ao cultivo de apenas uma variedade (Nogueira, 2005). Mais do que rendimento, o aumento da diversidade genética em cultivo pode também diminuir o ataque de doenças e pragas e, com isso, diminuir o uso de agrotóxicos. Isso foi constatado na China (Zhu et al., 2000), onde se verificou uma redução na incidência da doença bruzone no arroz em até $84 \%$, em resposta ao cultivo intercalado de mais de uma variedade. Entretanto, a transição para esses sistemas sustentáveis depende em muito de incentivos institucionais.

Em 2010, o Conselho de Direitos Humanos da ONU divulgou o Informe do Relator Especial, Olivier De Schutter, sobre o direito à alimentação. Baseando-se em extensa revisão da literatura científica publicada nos cinco anos anteriores, De Shutter (2010, p.1) identificou

a agroecologia como modo de desenvolvimento agrícola, que não só apresenta fortes conexões conceituais com o direito à alimentação, mas tem resultados comprovados para o progresso rápido na concretização desse direito humano para muitos grupos vulneráveis em vários países e ambientes. Além disso, a agroecologia proporciona as vantagens complementares às abordagens convencionais mais conhecidas de desenvolvimento de variedades de alto rendimento. E isso contribui fortemente para tornar mais amplo o desenvolvimento econômico.

Por outro lado, a agroecologia apresenta vantagens que se complementam com enfoques convencionais mais conhecidos, entre os quais a seleção genética de variedades de alto rendimento, contribuindo de forma expressiva para o desenvolvimento econômico mais amplo.

Há propostas associadas também ao tipo de parcerias pelas quais os pesquisadores devem optar.

Em vez de trabalhar com as elites e os governos locais, os conservacionistas devem aliar-se e apoiar os movimentos sociais que podem realmente realizam revoluções agrárias. Eles devem adotar um "novo paradigma" - uma reorientação das atividades de conservação, longe do foco em áreas protegidas e dirigido à sustentabilidade da paisagem manejada; longe de grandes proprietários de terras e dirigida para pequenos agricultores; longe do romantismo da natureza pura e dirigida para a qualidade do material da matriz agrícola e da matriz da natureza. No centro desse novo paradigma encontra-se a necessidade urgente de promover a justiça social e ambiental, sem as quais a conservação da biodiversidade, em última análise, torna-se apenas peça de retórica. (Perfecto; Vandermeer; Wright, 2009, p.10) 
Ainda de acordo com Perfecto et al. (cf. 2009, p.129), em muitos países em desenvolvimento, os pequenos agricultores e os sem-terra estão se organizando e exigindo o acesso à terra e ao seu direito a uma vida decente. Essas organizações de agricultores, cada vez mais estruturadas sob a bandeira da soberania alimentar, da agricultura sustentável e da conservação da biodiversidade, são um componente integral desse processo.

\section{Contribuições da pesquisa aos pequenos agricultores}

No século XX, os melhoristas de plantas utilizaram as variedades crioulas para desenvolver variedades modernas altamente produtivas, desde que o ambiente fosse criticamente modificado pelo uso de agroquímicos e maquinaria agrícola. Nesse tipo de pesquisa, não havia diálogo com os agricultores.

O Melhoramento Genético Participativo (MGP) de plantas propõe inverter a tendência histórica da separação entre agricultores e melhoristas, de modo que juntos eles possam desenvolver novas variedades ou melhorar o que já existe (Cleveland; Soleri, 2002). As principais características do MGP são:

(1) retomar e ampliar o interesse pelo uso e conservação de espécies ou variedades tradicionais pelos agricultores;

(2) evidenciar a capacidade protagonista dos agricultores e a efetividade do MGP - Modelo: genótipo x ambiente x social (Leclerc; d'Eeckenbrugge, 2012);

(3) promover o uso e a conservação in situ on farm.

O melhoramento participativo surgiu como uma alternativa aos programas conduzidos pelas instituições do setor formal de países em desenvolvimento. Essa abordagem surgiu em resposta aos impactos negativos, do ponto de vista agroecológico e socioeconômico, desses programas sobre os agricultores familiares que vivem em áreas marginais.

Projetos de MGP estão em andamento comumente em dezenas de países, incluindo o Brasil. Um deles vem sendo conduzido pelo Dr. Altair Machado da Embrapa (cf. Machado et al., 2007), o qual desenvolve projetos em estreita colaboração com agricultores, inclusive os assentados da reforma agrária. Em decorrência, variedades de polinização aberta de milho foram desenvolvidas em distintos ambientes, onde atualmente são cultivadas.

Outro exemplo de MGP encontra-se em andamento com a espécie frutífera Feijoa (Acca sellowiana), nativa da mata atlântica do sul do Brasil. Em seu trabalho de tese, Donazzolo (2012) desenvolveu um programa de MGP que:

(1) estabeleceu as estratégias participativas junto aos agricultores, as quais se mostraram eficientes para promover o uso e a conservação, sendo possível definir critérios de seleção;

(2) estabeleceu critérios e foi realizada a avaliação da população de trabalho;

(3) permitiu a seleção e a multiplicação das plantas promissoras;

(4) definiu a realização dos cruzamentos que foram realizados de forma participativa; 
(5) planejou a avaliação das progênies obtidas.

As evidências desse estudo revelaram que populações de A. Sellowiana têm sido manejadas e cultivadas, e, em algum grau, selecionadas e multiplicadas em paisagens antrópicas ao longo de pelo menos uma centena de anos.

A produção de híbridos intervarietais a partir das próprias variedades crioulas também se constitui em uma forma de MGP. Os agricultores vêm ao longo do tempo melhorando suas variedades de forma empírica e usando técnicas de seleção massal. O melhoramento constante dessas variedades é de fundamental importância para melhor adaptá-las aos novos ambientes de cultivo (por exemplo, em condições de baixa fertilidade e acidez dos solos). A produção de híbridos intervarietais é uma técnica de melhoramento que permite a manutenção da variabilidade genética das variedades, aliada ao efeito da heterose. Como as variedades crioulas apresentam alta diversidade genética, ou seja, as plantas são geneticamente distintas entre si e heterozigotas em muitos genes, elas produzem gametas geneticamente diferentes uns dos outros. Portanto, do cruzamento entre duas variedades resulta um híbrido intervarietal, composto por embriões descendentes distintos geneticamente, que se tornarão plantas. Por serem plantas híbridas, elas apresentam heterose ou vigor híbrido, o que possibilita um maior rendimento, comparativamente às variedades utilizadas nos cruzamentos.

De posse de um híbrido intervarietal, cada agricultor poderá praticar inovação, selecionando genótipos adaptados às distintas características em sua propriedade. Baseado nessas pressuposições, Munarini (2013), em sua dissertação de mestrado junto ao Programa de Pós-Graduação em Recursos Genéticos Vegetais da Universidade Federal de Santa Catarina, desenvolveu e testou, em parceria com agricultores da região oeste do estado, híbridos intervarietais de milho. Em condições de estresse hídrico, 38\% desses híbridos apresentaram comportamento igual à testemunha comercial em termos de produtividade. Além disso, verificou-se que os híbridos intervarietais apresentaram adaptação diferenciada aos diversos ambientes, o que possibilita o cultivo de variedades distintas para distintos ambientes, evitando a vulnerabilidade genética, quando um mesmo genótipo é cultivado em uma grande área.

O MGP deve ser desenvolvido no contexto de outras medidas agroecológicas, como aquelas destinadas a diminuir as pragas e as doenças. Para obter êxito na diminuição do uso de agrotóxicos baseando-se em alternativas biológicas é preciso:

(1) substituir o enfoque reducionista de controlar as pragas e proteger o cultivo (proteção de plantas), pelo enfoque sistêmico de manejo de pragas;

(2) integrar práticas de manejo ecológico de pragas;

(3) manejar o sistema de produção, com o objetivo de aumentar a complexidade, para reduzir as causas pelas quais os organismos nocivos se convertem em pragas, e potencializar a atividade dos inimigos naturais (Pérez, 2004).

São os(as) camponeses(as) ou agricultores(as), que por muitos anos vêm 
mantendo uma ou mais variedades crioulas em suas propriedades, os principais responsáveis por essas mudanças, sejam eles motivados pelo forte vínculo com a alimentação, cujos cultivos podem gerar ou não renda para a família, seja pela satisfação intrínseca em cultivar essas sementes, pelo gosto e prazer de fazer isso. Nos últimos anos, esses mantenedores têm sido denominados "guardiões de sementes". Dos inúmeros exemplos que existem no país, cabe mencionar o município de Ibarama, no Rio Grande do Sul (Barchet et al., 2007), cujas ações começaram em 1998 com a identificação de agricultores que mantinham sementes de milho crioulo no município. Com base nesse primeiro núcleo de agricultores, deu-se início a um processo de seleção e multiplicação de sementes em dez comunidades rurais. Essa iniciativa foi conduzida de forma a favorecer os próprios agricultores a atuarem como difusores e multiplicadores desses materiais junto aos seus vizinhos. Em 2002, com o crescimento do trabalho, foi organizado o "dia da troca de sementes crioulas". Nessa ocasião os agricultores levaram suas sementes e efetuaram a troca entre eles e a venda direta aos participantes que tinham interesse em semear variedades de milho crioulo. Também ficou acertado que o evento passaria a ocorrer todos os anos, sempre no mês de agosto. Em sua quinta edição, em 2006, promoveu-se um amplo debate com a participação de diversas entidades que desenvolvem ações e pesquisas orientadas ao uso e preservação de sementes crioulas. Nos depoimentos de pesquisadores e extensionistas rurais foram expostas as atividades que atualmente são executadas para proteger, preservar e multiplicar o patrimônio genético local e regional. Nessa oportunidade, contou-se com a presença de representantes da Embrapa Clima Temperado, do Centro de Apoio ao Pequeno Agricultor (Capa), de Sindicatos dos Trabalhadores Rurais (STR), de Secretarias Municipais de Agricultura, entre outras entidades. Além de uma Associação de Guardiões de Sementes, o município organiza uma feira anual no primeiro domingo de agosto.

Anteriormente, outra experiência de conservação pelo uso foi construída e vem sendo mantida no estado da Paraíba. Trata-se do Programa Sementes da Paixão, o qual é orientado para a identificação, o resgate e a conservação da agrobiodiversidade manejada pelos agricultores familiares. Esse Programa teve origem na década de 1970 quando as Comunidades Eclesiais de Base (CEB), ligadas à Igreja católica, começaram a promover na região nordeste do Brasil a organização de Bancos de Sementes Comunitários (BSC). A iniciativa foi motivada pela percepção de que o acesso às sementes constituía um elemento-chave na situação de miséria e dependência em que vivia grande parte das comunidades rurais do nordeste. Os bancos de sementes também foram considerados como uma oportunidade de abrir novos espaços organizativos para os trabalhadores rurais e, de fato, se constituíram numa das raízes da luta sindical e da luta partidária na região. $\mathrm{Na}$ Paraíba, esse trabalho foi realizado com o apoio da Comissão Pastoral da Terra, com as primeiras experiências tendo início a partir de doações de sementes compradas pela Igreja (Almeida; Cordeiro, 2002; Cunha, 2013). 
O trabalho passou a ser orientado a partir de três eixos: a melhoria na gestão dos bancos, a melhoria da qualidade física e genética das sementes e a valorização e conservação da diversidade local. Houve investimentos em capacitação, apoio à organização de eventos de formação e intercâmbio e financiamento para a aquisição de infraestruturas de armazenamento de sementes. Em 1995, já haviam sido estabelecidos 113 bancos de sementes comunitários em 52 municípios paraibanos. As sementes de "feijão-de-arranque", como são chamadas na Paraíba as sementes do feijão comum, Phaseolus vulgaris, feijão "macassa", como é chamado o feijão-de-corda, feijão-fradinho ou caupi, Vigna unguiculata, e as sementes de milho que foram distribuídas eram originadas de variedades melhoradas e, mesmo assim, essa ação foi importante para fortalecer a estratégia dos BSC (Santos et al., 2012; Almeida; Cordeiro, 2002).

Os Bancos de Sementes Comunitários (BSC) surgiram, assim, como uma estratégia complementar à prática tradicional do estoque de sementes em nível familiar, buscando com isso garantir o abastecimento anual desse recurso. $\mathrm{O}$ BSC é constituído a partir da organização de um grupo de agricultores e de um estoque inicial de sementes - que pode ser obtido por meio de doação ou a partir da contribuição dos próprios membros do grupo. As famílias associadas ao banco têm direito ao empréstimo de certa quantidade de sementes, que deve ser restituída ao final da colheita, em quantidade superior à que foi tomada emprestada. A taxa de juros, ou seja, a porcentagem de sementes que deve ser acrescida à quantidade emprestada no momento da devolução, é definida coletivamente entre os membros do banco e varia de grupo para grupo (Cunha, 2013).

A elevação do estoque do banco prevista por esse sistema de juros tem como objetivos possibilitar a ampliação do número de associados, o aumento da quantidade de sementes emprestada por família ou ainda formar estoques-reserva para enfrentar períodos de adversidades climáticas mais prolongadas (Almeida; Cordeiro, 2002). Nesse sistema, normalmente as famílias produzem e beneficiam suas próprias sementes, destinando uma parte da produção para o estoque comunitário, mas há também experiências em que a produção de sementes é feita de forma coletiva (ibidem).

É importante notar que as funções de um banco de sementes comunitário vão muito além do estoque coletivo de sementes. Frequentemente, é também por meio dos BSC que se articulam iniciativas de resgate de variedades antigas praticamente desaparecidas ou em risco de desaparecer, bem como a implantação de campos de multiplicação dessas variedades resgatadas. Quando determinadas sementes de interesse das famílias existem em apenas pequenas quantidades, bem como quando se quer reintroduzir nos roçados variedades em processo de desaparecimento, procede-se à multiplicação dessas sementes em campos coletivos, para que elas possam então ser disponibilizadas para empréstimos (Cunha, 2013). A autora afirma ainda que o papel dos BSC na conservação da agrobiodiversidade local, entretanto, tem claros limites. Normalmente, são armazenadas nos bancos as variedades de sementes que são plantadas em maiores quantidades 
pelos agricultores associados, bem como aquelas consideradas mais importantes do ponto de vista comercial, enquanto um número consideravelmente maior de espécies e variedades é guardado nos bancos de sementes familiares.

Nesses exemplos é possível constatar que todos os princípios a seguir mencionados podem ser seguidos: consumo e produção local; diversidade de espécies, variedades, formas de produção e serviços ambientais; pesquisa participativa; autonomia (energia, sementes, cadeia produtiva).

Além disso, o foco de todas as atividades mencionadas se basearam na compreensão das relações dos agroecossistemas, do manejo agroecológico da paisagem e na agricultura familiar.

\section{Conclusões}

É crescente o suporte científico e a percepção pública de que a exploração dos recursos naturais do planeta na forma como está sendo feita não aponta para a sustentabilidade e poderá trazer sérias consequências para a civilização humana. Essa exploração tem gerado enormes externalidades negativas, que são sistematicamente desconsideradas e omitidas. Assim, é urgente uma mudança na forma com que nos relacionamos com a biosfera.

Qualquer esforço é válido para alcançar a sustentabilidade particularmente para que as comunidades tradicionais, que produzem parte expressiva dos alimentos que consumimos e que, ao mesmo tempo, adotam práticas que conservam a biodiversidade, possam ascender a melhores condições de vida e superar a pobreza tendo como base conhecimentos, técnicas e inovações desenvolvidas durante milhares de anos.

Agrobiodiversidade e agroecologia são concepções inseparáveis e faces da mesma moeda. A agrobiodiversidade manejada pelas populações tradicionais, principalmente aquelas direcionadas ao uso, requer um complexo sistema de manejo e um profundo entendimento das relações do ecossistema. Essas formas milenares de manejo serviram como base para as diferentes formas de agricultura ecológica existentes na atualidade.

Atualmente é consenso que os benefícios da agroecologia estão associados a uma série de aspectos, entre eles:

(1) sociais, pois há aumento de capital e de coesão social reduzindo a migração;

(2) saúde, pois há melhora expressiva na qualidade da alimentação e nutrição e redução da dependência e exposição aos agrotóxicos e outros agroquímicos;

(3) ecológicos, em razão da redução da poluição da água e do solo e da conservação da biodiversidade. Práticas agroecológicas contribuem ainda para a recuperação de bacias hidrográficas, reduzem a dependência de insumos externos e são poupadoras de energia;

(4) segurança alimentar, pois a diversificação da produção em nível de propriedade melhora o acesso e uso dos recursos locais e estabiliza rendimentos em longo prazo; 
(5) redução da pobreza, já que há potencial para aumentar a renda resultante da venda de produtos frescos ou com maior valor agregado, com menores custos de produção e menor necessidade de comprar alimentos;

(6) diminuição do comprometimento de renda e endividamento familiar ao reduzir a necessidade de adquirir insumos externos caros;

(7) culturais, uma vez que os valores do conhecimento tradicional promovem e facilitam o diálogo de saberes, potencializando a criatividade e a inovação e capacitando a comunidade para tornar-se agente do seu próprio desenvolvimento e, por fim,

(8) do ponto de vista metodológico, pois, ao promover processos de pesquisa participativa, permite o entendimento holístico dos agroecossistemas, fornecendo ferramentas para avaliar e promover a sustentabilidade por meio de indicadores amigáveis aos agricultores.

A agroecologia é um modelo agrícola fundamental para a conservação e uso sustentável da biodiversidade, estratégia que se agrega à luta mundial de milhões de pequenos agricultores em busca da segurança e soberania alimentar.

\section{Notas}

1 Este artigo foi elaborado a partir da palestra apresentada no XXIV Seminário Internacional de Filosofia e História da Ciência sobre "tecnociência, valores e sociedade: assuntos correntes de pesquisa", no Instituto de Estudos Avançados, USP, São Paulo, em 2 de maio de 2013, como parte das atividades do Projeto Temático Fapesp 2011/516143: "Gênese e significado da tecnociência: das relações entre ciência, tecnologia e sociedade".

2 Para isso, consultar: <http://www.cbd.int/agro/>.

3 Toda essa documentação está disponível em: <www.agassessment.org $>$.

4 Pode-se acessar esse documento em: <http://www.ipcc.ch/>.

\section{Referências}

ALMEIDA, P.; CORDEIRO, A. Semente da paixão: estratégia comunitária de conservação de variedades locais no semiárido. Rio de Janeiro: ASPTA, 2002.

ALTIERI, M. A. Agroecology: the scientific basis of alternative agriculture. Boulder: Westview, 1987.

ALTIERI, M. A. (Ed.) Agroecologia: as bases cientificas da agricultura alternativa. Rio de Janeiro: PTA; Fase, 1999.

ANTONIOU, M. et al. Teratogenic effects of glyphosate-based herbicides: divergence of regulatory decisions from scientific evidence. Journal of Environmental and Analitycal Toxicology, Suppl.4, p.6, 2012.

AQUINO, A. M.; ASSIS, R. L. (Ed) Agroecologia: princípios e técnicas para uma agricultura orgânica sustentável. Brasília: Embrapa Informação Tecnológica, 2005. 
BADGLEY, C. et al. Organic agriculture and the globalfood supply. Renewable Agriculture and Food Systems, v.22, n.2, p.86-108, 2007.

BARBACENA, A. et al. (Org.) Los transgénicos en América latina y el Caribe: un debate abierto. Santiago: Editora Nações Unidas, 2004.

BARCHET, S. F. et al. Câmbio de sementes e seus guardiões: experiências de conservação da agrobiodiversidade em dois municípios do Rio Grande do Sul. Agriculturas, v.4, n.3, p.32-5, 2007.

BOEF, W. S. et al. (Org.) Biodiversidade e agricultores: fortalecendo o manejo comunitário. Porto Alegre: L\&PM, 2007.

BRUSH, S. B. (Ed) Genes in the field: on-farm conservation of crop diversity. Roma: IDRC/IPGRI/Lewis, 2000a.

. The issues of in situ conservation of crop genetic resources. In:

Genes in the field: on-farm conservation of crop diversity. Roma: IDRC/IPGRI/Lewis, 2000b. p.3-26.

CLEMENT, C. R. et al. Why extensive research and development did not promote use of peach palm fruit in Latin America. Agroforestry Systems, v.61-62, n.1-3, p.195-206, 2004.

CLEVELAND, D. A.; SOLERI, D. Farmers, scientists and plant breeding: knowledge, practice and the possibilities for collaboration. In: Farmers, scientists and plant breeding: integrating knowledge and practice. New York: Cabi Publishing, 2002 p.1-18.

CUNHA, F. L. Sementes da paixão e as politicas públicas de distribuição de sementes na Paraíba. 2013. Dissertação (Mestrado em Práticas em Desenvolvimento Sustentável) Universidade Federal Rural do Rio de Janeiro. Seropédica, 2013.

DAVIS, D. R. Declining fruit and vegetable nutrient composition: what is the evidence? HortScience, v.44, p.15-9, 2009.

DAVIS, D. R.; EPP, M. D.; RIORDAN, H. D. Changes in USDA food composition data for 43 garden crops, 1950 to 1999. Journal of the American College of Nutrition, v.23, p.69-82, 2004.

DE SCHUTTER, O. Promotion and protection of all human rights, civil, political, economic, social and cultural rights, including the right to development. Report submitted by the Special Rapporteur of Unesco on the right to food, 20 December 2010. Disponível em: <http://www.srfood.org/images/stories/pdf/officialreports/20110308_a-hrc-16-49_agroecology_en.pdf>. Acesso em: 15 jan. 2011.

DONAZZOLO, J. Conservação pelo uso e domesticação da feijoa na Serra Gaúcha, RS. 2012. Tese (Doutorado em Recursos Genéticos Vegetais) - Universidade Federal de Santa Catarina. Florianópolis, 2012.

ELLSTRAND, N. C. Dangerous liaisons? When cultivated plants mate with their wild relatives. Baltimore: The Johns Hopkins University Press, 2003.

FRAME, D. J.; STONE, D. A. Assessment of the first consensus prediction on climate change. Nature Climate Change, v.3, n.4, p.357-9, 2013.

GARRITY, D. P. et al. Evergreen agriculture: a robust approach to sustainable food security in Africa. Food Security, v.2, n.3, p.197-214, 2010. 
GLIESSMAN, S. R. Agroecology: researching the ecological basis for sustainable agriculture. New York: Springer Verlag, 1990.

1998.

Agroecology: ecological processes in sustainable agriculture. Ann Arbor: Chelsea,

GOMES, J. C. C.; BORBA, M. A moderna crise dos alimentos: oportunidades para a agricultura familiar? Agroecologia e Desenvolvimento Rural Sustentável, v.3, p.52, 2000.

HOWARD, A. An agricultural testament. London: Rodales, 1943.

ICPJ. A agricultura camponesa e as energias renováveis. Porto Alegre: ICPJ, 2008.

IPCC. International panel on climate changes 2013: Summary for policymakers. In: STOCKER, T. F. et al. (Ed.) Climate change 2013: The physical science basis. Contribution of working group 1 to the Fifth Assessment Report of the Intergovernmental Panel on Climate Change. Cambridge; New York: Cambridge University Press, 2015.

JARVIS, A.; LANE, A.; HIJMANS, R. J. The effect of climate change on crop wild relatives. Agriculture Ecosystem and Environment, v.126, n.1-2, p.13-23, 2008.

JESUS, E. L. Diferentes abordagens de agricultura não convencional: história e filosofia. In: AQUINO, A. M.; ASSIS, R. L. (Ed) Agroecologia: princípios e técnicas para uma agricultura orgânica sustentável. Brasília: Embrapa Informação Tecnológica, 2005. p.21-48.

KOGAN, M.; BAJWA, W. I. Integrated pest management: a global reality? Anais da Sociedade de Entomologia do Brasil, v.28, n.1, p.1-25, 1999.

LACEY, H. Values and objectivity in science. The current controversy about transgenic crops. Lanham: Lexington Books, 2005.

LECLERC, C.; D’EECKENBRUGGE, G. C. Social organization of crop genetic diversity. The $\mathrm{G} \times \mathrm{E} \times \mathrm{S}$ interaction model. Diversity, v.4, p.1-32, 2012.

LEWONTIN, R. It ain't necessarily so. The dream of the human genome and other illusions. New York: New York Review Books, 2000.

MACHADO, A. T.; MACHADO, C. T. T. Melhoramento participativo de cultivos no Brasil. In: BOEF, W. S. et al. (Org.) Biodiversidade e agricultores: fortalecendo o manejo comunitário. Porto Alegre: L\&PM, 2007. p.93-102.

MAXTED, N.; FORD-LOYD, B. V.; HAWKES, J. G. (Ed.) Plant genetic conservation. London: Chapman \& Hall, 1997.

MAXTED, N. et al. A practical model for in situ genetic conservation - complementary conservation strategies. In: MAXTED, N.; FORD-LOYD, B. V.; HAWKES, J. G. (Ed.) Plant genetic conservation. London: Chapman \& Hall, 1997. p.339-67.

McINTYRE, B. D. et al. (Ed.) Synthesis Report. International Assessment of Agricultural Knowledge, Science and Technology for Development (IAASTD). Washington: UNDP/Unep/Unesco/WHO/GEF, 2008. Disponível em: <http://www.unep.org/ dewa/agassessment/reports/IAASTD/EN/Agriculture\%20at\%20a\%20Crossroads_ Synt hesis\%20Report\%20(English).pdf>. Acesso em: 8 jul. 2013.

MOLlisON, B.; HOLMGTEN, D. Permaculture I. Melbourne: Transworld, 1978.

MUNARINI, A. Avaliação de híbridos intervarietais de milho em sistemas de produção 
camponesa de Santa Catarina. 2013. Tese (Mestrado em Recursos Genéticos Vegetais) - Universidade Federal de Santa Catarina. Florianópolis, 2013.

NODARI, R. O.; GUERRA, M. P. La bioseguridad de las plantas transgénicas. In: BARBACENA, A. et al. (Org.) Los transgénicos en América latina y el Caribe: un debate abierto. Santiago: Editora Nações Unidas, 2004. p.111-22.

NODARI, R. O.; TENFEN, S. Z. A.; DONAZZOLO, J. Biodiversidade: ameaças e contaminação por transgenes. Revista Internacional de Direito e Cidadania, v.v. p.1-13, abril, 2011.

NOGUEIRA, A. M. Avaliação da produtividade e vigor vegetativo de linhagens das cultivares catuai-vermelho e catuai-amarelo (Coffea arábica L.) plantadas individualmente e em diferentes combinações. Revista Ciência e Agrotecnologia, v.29, n.1, p.2277-3333, 2005.

NORGAARD, R. B. A base epistemológica da agroecologia. In: ALTIERI, M. A. (Ed.) Agroecologia: as bases cientificas da agricultura alternativa. Rio de Janeiro: PTA/Fase, 1989. p.42-8.

PADUA, J. A. (Org.) Seminário preparatório ao Encontro Nacional de Agroecologia. Rio de Janeiro, 27 e 28 de julho de 2001. Rio de Janeiro, agosto de 2001.

PÉREZ, N. Manejo ecológico de plagas. La Habana: Centro de Estudios de Desarrollo Agrario y Rural (Cedar), 2004.

PERFECTO, I.; VANDERMEER, J.; WRIGHT, A. Matrix nature: linking agriculture, conservation and food sovereignty. London: Earthscan, 2009.

PRETTY, J. N. et al. Resource-conserving agriculture increases yields in developing countries. Environmental Science and Technology, v.40, n.4, p.1114-9, 2006.

SANTOS, A. S. et al. Pesquisa e politica de sementes no semiárido paraibano. Aracaju: Embrapa Tabuleiros Costeiros, 2012. (Documentos 179)

SANTOS, K. L. et al. Traditional knowledge and management of feijoa (Acca sellowiana) in Southern Brazil. Economic Botany, v.63, p.204-14, 2009.

SILVA, M. T. A importância da agrobiodiversidade na (agri)cultura camponesa. In: ICPJ. A agricultura camponesa e as energias renováveis. Porto Alegre: ICPJ, 2008. p.46-8.

STEINER, R. Agriculture: a course of eight lectures. London: Rudolf Steiner Press, 1976.

STELLA, A.; KAGEYAMA, P. (Coord.) Agrobiodiversidade e diversidade cultural. Brasília: MMA. 2006.

STELLA, A.; KAGEYAMA, P.; NODARI, R. O. Políticas públicas para a agrobiodiversidade. In: STELLA, A.; KAGEYAMA, P. (Coord.) Agrobiodiversidade e diversidade cultural. Brasília: MMA. 2006. p.41-56.

STHAPIT, B. et al. Informal seed systems and on-farm conservation of local varieties. In: THIJSSEN, M. H. et al. (Ed.) Farmers, seeds and varieties. Wageningen: Wageningen International, 2008. p.133-6.

THIJSSEN, M. H. et al. (Ed.) Farmers, seeds and varieties. Wageningen: Wageningen International, 2008. 
TUXILL, J. The biodiversity that people made. WorldWatch, v.3, n.3, p.24-35, 2000.

WHITSON, A. R.; WALSTER, H. L. Soils and soil fertility. St. Paul MN: Webb, 1912. Disponível em: <http://books.google.com.au/books?id=8SguAAAAYAAJ\&dq=editi ons3AJ2lm1K7DxBIC\&q=Dobenecks\#v=onepage\&q=Dobenecks\&f=false $>$. Acesso em: 29 dez. 2013.

ZHU, Y. et al. Genetic diversity and disease control in rice. Nature, v.406, p.718-22, 2000 .

RESUMO - A agrobiodiversidade é a parcela da biodiversidade constituída por um conjunto de organismos e ecossistemas que apresentam fortes relações com os seres humanos, podendo ser domesticados, semidomesticados, cultivados ou manejados pelo homem. Essa diversidade, conservada há séculos pelo uso (conservação in situ ou conservação on farm) pelos pequenos agricultores em todas as regiões do planeta, encontra-se ameaçada. De um lado, a agricultura industrial ou química através de suas práticas, ricas em insumos químicos, provoca muitas externalidades negativas, até recentemente pouco consideradas. De outro lado, as mudanças climáticas, igualmente, produzem efeitos adversos à diversidade genética. No entanto, as preocupações com a produção de alimentos de alta qualidade biológica em sistemas agrícolas sustentáveis remontam ainda o início do século XX. Dentre os vários sistemas agrícolas sustentáveis ou alternativos, a agroecologia apresenta vários atributos favoráveis: não faz uso de insumos químicos, é sustentável em todas as suas dimensões, faz uso de grande diversidade genética no cultivo, é socioeconômico-associada, estimula as relações de vizinhança e produz alimentos com alta qualidade biológica e nutricional. No âmbito da agroecologia e não da agricultura industrial ou química, há inúmeras oportunidades para a C\&T desenvolver pesquisas participativas, contextualizadas, que podem empoderar tanto a agricultura familiar quanto as comunidades tradicionais no aperfeiçoamento dos processos e princípios agroecológicos utilizados. Assim, muitas das externalidades negativas atualmente inadmissíveis poderiam ser evitadas.

PALAVRAS-CHAVE: Agrobiodiversidade, Conservação in situ, Conservação on farm, Sistemas agrícolas sustentáveis, Lacunas do conhecimento, Diversidade em cultivo.

ABSTRACT - Agrobiodiversity is the portion of biodiversity consisting of a set of organisms and ecosystems that has strong relationships with humans, being domesticated, semi-domesticated, cultivated or managed by human beings. This diversity, which has been preserved by the practices (in situ on-farm conservation) of smallholder farmers in all regions of the world, is under threat. On one hand, industrial or chemical agriculture, because their practices are rich in external chemical inputs, causes many negative externalities that have not been considered much until recently. On the other hand, climate changes also produce adverse effects on the genetic diversity. However, since the beginning of the twentieth century concerns about the production of high quality organic foods in sustainable agricultural systems have been affirmed. Among several alternative or sustainable farming systems, agroecology comes with many favorable features: it makes no use of agrochemicals, it is environmentally sustainable, it makes use of high genetic diversity in cropping, it is socio-economically associated, it stimulates neighborhood relations, and it has food products of high biological quality. In the con- 
text of agroecology, but not in industrial or chemical agriculture, there are numerous opportunities for science and technology to develop participatory research, contextualized, that can empower family farming as well traditional communities in improving agroecological principles and processes. Thus, many of the currently unacceptable negative externalities could be avoided.

KErWORDS: Agricultural biodiversity, Conservation in situ, Conservation on farm, Sustainable agriculture systems, Gaps in the knowledge, Diversity in cropping.

Rubens Onofre Nodari é doutor em Genética pela Universidade da Califórnia, Davis, professor titular da Universidade Federal de Santa Catarina, professor junto ao Curso de Agronomia e ao Programa de Pós-graduação em Recursos Genéticos Vegetais da Universidade Federal de Santa Catarina, Florianópolis, Brasil.

@ - rubens.nodari@ufsc.br

Miguel Pedro Guerra é doutor em Ciências pela Universidade de São Paulo, professor titular da Universidade Federal de Santa Catarina, professor junto ao Curso de Agronomia e ao Programa de Pós-graduação em Recursos Genéticos Vegetais da Universidade Federal de Santa Catarina, Florianópolis, Brasil. @-miguel.guerra@ufsc.br

Recebido em 26.5.2014 e aceito em 31.7.2014.

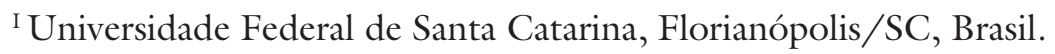

II Universidade Federal de Santa Catarina, Florianópolis/SC, Brasil. 
